\title{
A dor sem nome: análise da experiência de mães que perderam filhos
}

\author{
Named pain: analysis of the experience of mothers who have lost children \\ Dolor nombrado: análisis de la experiencia de madres que han perdido a los hijos
}

Recebido: 09/01/2021 | Revisado: 14/01/2021 | Aceito: 16/01/2021 | Publicado: 19/01/2021

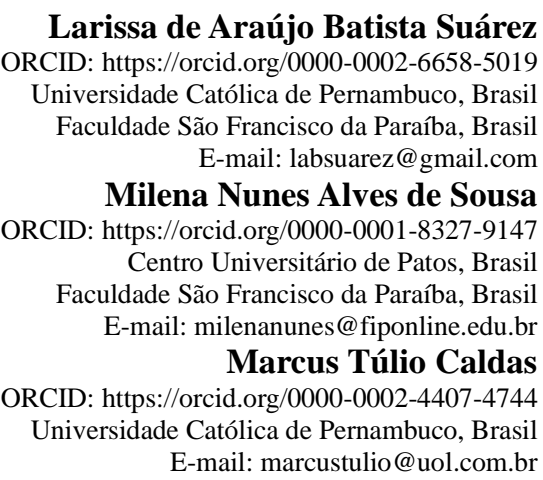

\begin{abstract}
Resumo
Objetivou-se, portanto, analisar a experiência de mães que perderam filhos. Trata-se de um estudo de empírico com nove mães que participam do grupo Mães da Pietá. As narrativas foram analisadas com base nas categorias de análise: O relato da morte; A experiência de perder um filho, os sentimentos mais evidentes após a perda; A dinâmica familiar antes e após a perda; Momentos e memórias; O tempo necessário para resposta emocional; Principais mudanças físicas e emocionais. Identificou-se que o apoio familiar, a espiritualidade, a continuidade do vínculo com o filho falecido, a interação e o desenvolvimento de ações através do grupo Mães da Pietà foram fundamentais na reconstrução de sentido da vida. É importante ressaltar que o tipo de morte e o tempo transcorrido são essenciais na compreensão do enfrentamento. Com base nas narrativas das mães enlutadas foi possível constatar que o luto é experienciado de forma diferente, permitindo a cada mãe desenvolver sua relação com a perda de forma singular.
\end{abstract}

Palavras-chave: Luto; Espiritualidade; Eixos de sentido; Valores existenciais.

\begin{abstract}
The objective was, therefore, to analyze the experience of mothers who lost children. It is an empirical study with nine mothers who participate in the group Mother of Pietà. The narratives were analyzed based on the categories of analysis: The report of death; The experience of losing a child, the most evident feelings after the loss; Family dynamics before and after the loss; Moments and memories; The time needed for emotional response; 6 . Main physical and emotional changes. It was identified that family support, spirituality, the continuity of the bond with the deceased child, interaction and the development of actions through the group Mother of Pietà were fundamental in the reconstruction of the meaning of life. It is important to emphasize that the type of death and the time elapsed are essential in understanding the coping. Based on the narratives of bereaved mothers, it was possible to verify that grief is experienced differently, allowing each mother to develop her relationship with the loss in a unique way.
\end{abstract}

Keywords: Mourning; Spirituality; Axes of meaning; Existential values.

\section{Resumen}

Por lo tanto, el objetivo era analizar la experiencia de las madres que perdieron hijos. Es un estudio empírico con nueve madres que participan en el grupo Mãe da Pietá. Las narraciones se analizaron en función de las categorías de análisis: El informe de la muerte; La experiencia de perder a un hijo, los sentimientos más evidentes después de la pérdida; Dinámica familiar antes y después de la pérdida; Momentos y recuerdos; El tiempo necesario para la respuesta emocional; Grandes cambios físicos y emocionales. Se identificó que el apoyo familiar, la espiritualidad, la continuidad del vínculo con el niño fallecido, la interacción y el desarrollo de acciones a través del grupo Madre de Pietà fueron fundamentales en la reconstrucción del sentido de la vida. Es importante enfatizar que el tipo de muerte y el tiempo transcurrido son esenciales para comprender el afrontamiento. Basado en las narraciones de madres desconsoladas, fue posible verificar que el dolor se experimenta de manera diferente, permitiendo que cada madre desarrolle su relación con la pérdida de una manera única.

Palabras clave: Duelo; Espiritualidad; Ejes de significado; Valores existenciales. 


\section{Introdução}

O ser humano busca em sua essência interagir com os seus iguais, dentre os motivos que permeiam a vontade de construir uma família destaca-se a concepção de um filho-(Fonnegra, 2001). Após a constituição de uma família os laços são construídos, as relações são estruturadas e as responsabilidades definidas, entre as quais cuidar e proteger figuram entre as principais. Contudo, qualquer família pode se deparar com situações de morte e o luto passa a ser visto como um processo doloroso e inevitável dentro do ciclo familiar, difícil de ser aceito para os que sofrem a perda (Bromberg, 2000).

O processo de perda é estruturado em dois indivíduos, o que vai a óbito e o que lamenta a perda, este passa a viver as fases do luto com o sentimento de que algo lhe foi retirado, a falta do outro. Quando a vivência do luto é "saudável" o enlutado passa a reviver as experiências construídas com o ente querido através das lembranças, construindo em seguida um replanejamento de sentido de vida. É fato que toda perda requer um luto, é preciso viver a experiência para só depois seguir em busca de um novo sentido (Walsh \& Mcgoldrick, 1998).

Diante da experiência de perda é fundamental que o enlutado busque suporte emocional e social. O primeiro pode ser atingido pela terapia e o social pode ser encontrado junto à família, Igreja e/ou aos Grupos de Ajuda Mútua (GAMs). Os GAMs são instituídos por pessoas que compartilham situações semelhantes na vida, como acontecimentos que envolvem o sofrimento, a dor, a perda, o luto, entre outros. Os membros desses grupos geralmente são pessoas que tiveram experiências semelhantes, tais grupos desenvolvem ações em prol da ajuda mútua, através de estudos, ações sociais, orações e espiritualidade (Melo, Maia Filho \& Chaves, 2014).

Ante a tais ponderações, objetivou-se analisar a experiência de mães que perderam filhos. Justifica-se o estudo pelo entendimento de que novas pesquisas sobre o objeto de estudo são relevantes, pois é fundamental "aprofundar a relação de 'desligamento' entre a mãe enlutada e o filho falecido, tendo em vista que se refere a situações dolorosas enfrentadas por mães enlutadas capazes de gerar doenças no corpo e na alma" (Suárez, Sousa \& Caldas, 2020).

\section{Metodologia}

Pesquisa qualitativa, alicerçada na compreensão do discurso consciente dos participantes do estudo sobre o assunto abordado. Portanto, envolve elementos não mensurados numericamente, pois desenvolve seus trabalhos fundamentados em um meio de significado, crenças, valores e atitudes (Minayo, 2010). O lócus de estudo foi o município de Patos, Paraíba, Brasil. Abordou-se um grupo de mães que perderam seus filhos, denominado de Mães da Pietà.

A idealização do grupo partiu de um padre de uma das paróquias locais e um médico cardiologista que atende pessoas em estado terminal, pois estava crescente o número de mães enlutadas em busca de apoio. Os encontros grupais tiveram início entre o final de 2009 e o início de 2010 com sete membros e hoje conta com 35 mães.

A amostra da pesquisa foi composta por nove mães. Incluíram-se aquelas mães com conviviam com os filhos antes da perda. Excluíram-se mães de natimorto e mulheres com idade inferior a 18 anos. A composição da amostra delineou-se pelo critério de saturação dos dados e por adesão espontânea. Apresentam-se as participantes da pesquisa na sequência. Ressalta-se que foram usados codinomes, escolhidos pelas próprias mães da amostra, que optaram pelos nomes das "Santas" de devoção.

1. Maria - 57 anos de idade, letra inicial do nome do filho "I", sexo masculino, falecido aos 3 anos e 3 meses de idade, tipo de morte acidental no trânsito (Atropelamento), ano da morte 1992, tempo transcorrido 24 anos.

2. Isabel - 50 anos de idade, letra inicial do nome do filho "R", sexo masculino, falecido aos 20 anos de idade, tipo de morte suicídio (arma de fogo), ano da morte 2007, tempo transcorrido 10 anos.

3. Conceição - 56 anos de idade, letra inicial do nome do filho "T", sexo masculino, falecido aos 24 anos de idade, tipo de morte acidental no trânsito (automobilístico), ano da morte 2010, tempo transcorrido 7 anos. 
4. Francisca - 57 anos de idade, letra inicial do nome do filho "J", sexo masculino, falecido aos 20 anos de idade, tipo de morte acidental no trânsito (automobilístico), ano da morte 2002, tempo transcorrido 15 anos.

5. Rita de Cássia - 47 anos de idade, letra inicial do nome do filho "JL", sexo masculino, falecido aos 15 anos de idade, tipo de morte natural (Infarto), ano da morte 2010, tempo transcorrido 7 anos.

6. Aparecida - 64 anos de idade, letra inicial do nome da filha " $A$ ", sexo feminino, falecida aos 19 anos de idade, tipo de morte acidental no trânsito (automobilístico/carbonizada), ano da morte 2003, tempo transcorrido 14 anos.

7. Das Graças - 64 anos de idade, letra inicial do nome do filho "W", sexo masculino, falecido aos 28 anos de idade, tipo de morte acidental no trânsito (automobilístico/carbonizado), ano da morte 2012, tempo transcorrido 5 anos.

8. Rosa Mística - 52 anos de idade, letra inicial do nome do filho "P”, sexo masculino, falecido aos 19 anos de idade, tipo de morte acidental no trânsito (motociclista), ano da morte 2016, tempo transcorrido 1 anos.

9. Fátima - 60 anos de idade, letra inicial do nome do filho "JA", sexo masculino, falecido aos 22 anos de idade, tipo de morte acidental no trânsito (motociclista), ano da morte 2011, tempo transcorrido 6 anos.

A pesquisa foi submetida ao Comitê de Ética da Universidade Católica de Pernambuco (UNICAP) e, após a aprovação, foi marcado o primeiro encontro para explicar as características da pesquisa e seus objetivos, bem como solicitar a anuência das mães. O primeiro encontro ocorreu na residência de uma das mães e estiveram presentes os fundadores do grupo, os quais auxiliaram para a concretização do primeiro encontro.

Após a reunião e com a adesão espontânea das mães, foram marcados os dias, os horários e lugar para os encontros, iniciando-se a coleta dos dados. As entrevistas foram conduzidas individualmente, em sala confortável, climatizada e silenciosa, disponibilizada pela paróquia. O tempo de duração das entrevistas variou entre 00h:41m:28s e 01h:48m:29s.

O instrumento de coleta de dados contemplou a entrevista narrativa proposta por Benjamin (1994), em que o narrador se empenha na elaboração da experiência, deixa de assumir a postura de um simples expectador e torna-se um elemento ativo no processo de elaboração da experienciação tornando-se, também, protagonista de uma história diante da visão desenvolvida em um determinado lugar. A entrevista narrativa torna-se, ainda, "instrumento" disponível para pesquisa, através da conversação ininterrupta entre narrador e pesquisador e inicia-se através de uma pergunta disparadora e algumas perguntas auxiliares para desvelar o fenômeno principal da pesquisa (Schmidt, 1990).

A pergunta disparadora foi fundamenta na experiência da perda. Ao realizar a pergunta disparadora, outras questões emergiram como auxiliares à compreensão da experiência da perda de forma detalhada. A pergunta disparadora foi: Como foi para você a experiência de perder um (a) filho (a)? E as auxiliares contemplaram as indagações: 1) Antes da perda de seu (sua) filho (a) como era sua relação com os membros de sua família? 2) Ocorreram mudanças em você e em sua dinâmica familiar com a perda de seu (sua) filho (a)? 3) Seria possível relatar como foram os primeiros momentos após a perda? 4) Quanto tempo foi suficiente para você responder emocionalmente à perda de seu (sua) filho (a)? 5) Você notou mudanças significativas em sua saúde física e/ou mental, gerada após a perda do seu (sua) filho (a)?

Foi adotada a análise de conteúdo. Ao estruturar um resultado fundamento da nesta análise encontram-se respostas mediante verificação de hipóteses e/ou questões, evidenciando ou não as afirmações estruturadas antes da investigação ou mediante conteúdos manifestos, em que os sentidos envoltos no aparentemente não dito, apresentam-se de forma contida (Bardin, 1979).

Na utilização desta técnica objetivou analisar as entrevistas realizadas individualmente com mães que participam de um grupo de apoio mútuo no sentido de compreender como cada membro estruturou sua forma de enfrentamento diante de experiências de perda.

Para análise dos resultados da referida pesquisa utilizou-se da Logoterapia, um novo campo de estudo direcionado para uma perspectiva espiritual que se fundamenta na análise existencial, estruturado não apenas no sofrimento do ser humano, 
mas também na origem do seu sentido de vida (Frankl, 1978). Foram contemplados três eixos de sentido: a liberdade da vontade, a vontade de sentido e o sentido da vida (Frankl, 2011). O primeiro é a liberdade da vontade, o ser humano é livre e responsável, no entanto, há determinantes psicofísicas e sociais que podem influenciar sua forma de interagir e ver o mundo. Todavia apesar de tais condicionantes, o humano está livre para tomar decisões diante das possibilidades de vida (Aquino, 2014).

Como segundo eixo, a vontade de sentido representa o objetivo natural do ser humano em efetuar sentidos e propósitos. Ressalta-se que a vontade de sentido difere da vontade de prazer e de poder, já que ambas são desenvolvidas após a frustração da vontade de sentido. O último eixo corresponde ao sentido da vida, em que a existência humana torna-se autêntica se vivida de forma autotranscendente, ou seja, a vida possui um sentido incondicional em que o ser humano vive por ideias e valores (Fonseca, 2014).

O sentido pode abordar as três perspectivas são: o sentido na vida, que trata o aqui e o agora, há um sentido latente a ser desvelado na consciência; o sentido da vida trata-se de um sentido abrangente sobre a totalidade da vida, em divergência ao sentido momentâneo; e o sentido do mundo, que se refere a um suprassentido superior aos sentidos estudados até o presente momento e a busca por esse suprassentido estaria na religião (Aquino, 2014).

\section{Resultados e Discussão}

A forma de experienciar a morte e a perda ocorrem de formas diferentes, o tipo de morte, as circunstâncias da perda e a estrutura de suporte social, tendem a influenciar na forma de enfrentamento das mães enlutadas. Os sub-tópicos a seguir apresentam de forma detalhada os momentos mais significativos dessa experiência.

\subsection{Narrando à dor através dos fatos}

Maria: "Era uma festa de páscoa na escola e "I" representaria um anjinho, na hora da apresentação ele se isolou, ficou caladinho, era como se não estivesse ali. Na volta para casa, eu disse a meu esposo: esquecemos o pão. Voltamos e meu esposo entra para comprar o pão. "I" diz: mainha deixa eu ficar com meu pai. Eu respondo: seu pai já está voltando, e "I" diz: Oh mainha você não está deixando o filhinho ficar com o pai? Essa foi a última frase que ouvi do meu filho (choro e reflexão) talvez fosse a Deus Pai que ele se referia. Quando eu abro a porta para ele entrar na panificadora, no lugar de entrar ele corre para o meio da rua, e eu saio correndo, foi um segundo que valeu por uma vida, a vida do meu filho. "I", ainda foi socorrido para o hospital de Campina Grande - PB com vida, ainda chorou. Mas, nesse momento eu já convivia com a dor e também com a culpa, porque uma mãe se sente culpada até pelo que ela não tem culpa.... Porque eu não corri mais? Porque eu não peguei? Porque fui comprar pão? (choro e reflexão). Ao chegar em Campina Grande - PB ainda dentro da ambulância eu fui pedir perdão, e ele olhou para mim e riu. Ele faleceu após a cirurgia".

Diante da narrativa de "Maria" é possível identificar que "I" foi vítima de uma morte inesperada/ acidental, uma fatalidade na qual "Maria" sente dor, chega a culpar-se, a buscar "porquês", mas em seguida ela é prevalecida por uma paz que transcende em suas palavras e atos, paz definida por ela como "Fé".

Para Frankl (2011) o homem não seria capaz de ultrapassar a diferença dimensional entre o mundo humano e o divino, mas, seria possível ao homem, buscar o divino por intermédio da fé. "Maria" acredita em uma missão que foi cumprida, ela não perdeu seu filho, o "devolveu” e é nessa perspectiva professa sua fé.

Isabel: "Era um dia normal, " $R$ " não quis lanchar, meu esposo estava trabalhando fora e logo no início da noite ligou para " $R$ ” e disse: vá para casa sua mãe está sozinha com seu irmão. Deu 10h, 11h, 12h, 1h da madrugada e nada de “ $R$ ” chegar, às 2 hs o telefone tocou, era a ex-namorada dizendo que ele tinha ligado dizendo que iria se matar, ela disse ter perguntado onde " $R$ " estava e ele não respondeu, disse apenas que amanhã todos irão saber. Ligamos para os amigos, 
ninguém sabia. Meu filho mais novo estava muito nervoso e assim amanhecemos o dia. Meu esposo chegou do trabalho e foi até a polícia, nenhuma notícia. Às 9:30hs chegou um policial fazendo perguntas sobre " $R$ ", em seguida descreveu o carro dele e perguntou se ele tinha inimigos, na hora perguntei: ele morreu? O policial respondeu: sim, a senhora quer ir lá? Fiquei sem reação"

"Isabel" apresenta muita riqueza de detalhes em seu relato, são palavras cobertas de emoção e intensidade que permitem a mesma reviver cada momento com ressignificação.

Segundo "Isabel", "R" nunca apresentou comportamentos desviantes ou psicopatologias que viessem a chamar sua atenção, era um jovem discreto e centrado, no entanto, há pouco tempo havia encerrado um relacionamento aparentemente conturbado. De acordo com Frankl (1991) o suicídio tem influência psicossocial e é um fenômeno característico da sociedade contemporânea, manifesta-se no tédio, na indiferença e na falta de sentido, definido pela Logoterapia como vazio existencial. Nesse cenário, a morte de "R" foi considerada por "Isabel" como um ciclo que se encerrava, uma joia que se devolvia.

Rita de Cássia: "Um ano antes de devolver "JL”, o médico me diagnosticou com depressão pós-parto. Eu sentia um grande vazio, não tinha vontade de fazer nada, apenas deitar e chorar. Fui fazer tratamento em João Pessoa - PB e deixei "JL" trabalhando com o pai dele. Viajei no domingo e na quarta-feira minha prima me ligou e disse que "JL" teve um desmaio no banheiro, foi um infarto, ele faleceu. Voltei [...]. Hoje não sei explicar exatamente se o que eu estava sentindo era depressão ou um pressentimento. Eu tinha em "JL" uma referência, ele representava uma fortaleza, [...] eu me sentia forte porque tinha a presença dele. Todos [...] da rua gostavam dele [...]. Ele era tão puro e bom, que às vezes imagino que ele não era desse mundo. "JL" veio com uma missão a Terra e a missão foi cumprida".

"Rita de Cássia" relata já ter desenvolvido depressão antes da perda do filho, contudo, enfatiza que após a perda de "JL" os episódios de depressão ressurgiram mais fortes. Também evidencia um vazio diante da perda, mas em seguida relata que "JL" cumpriu sua missão. No seu relato apresenta episódios de dor aguda repleta de ansiedade e saudades do filho. Para Parkes (1998), com a perda, tais sentimentos podem ser recorrentes, mas tendes a diminuir com o tempo, reincidindo apenas a partir de uma lembrança/episódio que remeta à pessoa perdida.

\subsection{Relatos e sentimentos diante da experiência de perder um filho}

A experiência de perda pode ser caracterizada de diversas formas, o luto pode evoluir do normal ao patológico. Alguns pontos devem ser considerados no momento da perda, como: idade do enlutado, idade e papel do falecido, causas e circunstâncias da perda, personalidade do enlutado, variáveis sociais etc. (Bowlby, 1989).

Portanto, "Francisca" apresenta sua narrativa evidenciando que não há palavras para descrever a experiência da devolução de um filho. "Foi a pior experiência da minha vida, nunca imaginei que iria devolver um filho, meu mundo desabou de uma hora para outra. Ele era um jovem cheio de sonhos, ver tudo acabar assim de repente. Não há palavras para descrever a dor dessa experiência, tenho dentro de mim uma dor sem nome!”

Parkes (1998) ratifica que dentre os lutos, o materno é o mais complexo na sua elaboração, com uma duração mais prolongada gerando, assim, um sofrimento mais intenso.

Na narrativa de "Das Graças" ela apresenta aflição por não ver seu filho concretizar o ciclo vital. "Nunca imaginai receber um filho morto na minha casa, sempre pensei que eu iria morrer primeiro. Eu já perdi meu pai, minha mãe, meu esposo, mais a morte do meu filho doeu muito mais, a saudade deixa um buraco enorme em meio a um vazio sem nome".

É preciso que o enlutado defina as próximas etapas a serem vividas futuro-presente-passado. Uma vez que todas as experiências ficam armazenadas no passado, torna-se crucial definir presente e futuro (Aquino, 2013). 


\subsection{Dinâmica familiar antes e depois da perda}

Segundo Minuchin (1982) a família é um sistema relacional primário instituído de forma hierárquica, os membros da família são definidos como subsistemas, a mudança em um subsistema pode infligir em todo ou partes. Logo, a morte de um membro da família pode promover mudanças negativas ou positivas em todo o sistema, resultando em transformações nos subsistemas.

O óbito é um evento particular e relevante no ciclo familiar, uma vez que após esse evento surgem variações de posicionamento entre os membros, variações essas que não surgiriam sem a vivência desse ciclo (Friedman, 1995).

O Quadro 1 apresenta a dinâmica familiar da amostra estudada antes e após a perda do (a) filho (a) elencando com base nas narrativas das mães. Pelos relatos, nenhuma família permaneceu com a estrutura inicial.

Quadro 1. Dinâmica familiar antes e após a perda de um (a) filho (o).

\begin{tabular}{|c|c|c|}
\hline \multicolumn{2}{|r|}{ Dinâmica familiar antes da perda } & Dinâmica familiar após da perda \\
\hline \multicolumn{3}{|r|}{ Maria } \\
\hline $\begin{array}{l}1 . \\
2 . \\
3 . \\
4 .\end{array}$ & $\begin{array}{l}\text { Vida devotada a família; } \\
\text { Alegria: esposo e filhos; } \\
\text { Momentos eram planejados apenas em família; } \\
\text { Acreditava-se em Deus, mas não professava a }\end{array}$ & $\begin{array}{l}\text { 1. } \quad \text { A família passa a buscar a Igreja; } \\
\text { 2. } \quad \text { A morte de "I" catequisou a família; } \\
\text { 3. } \quad \text { Filha afirma que a família é mais feliz após a perda do } \\
\text { irmão, porque encontrou a espiritualidade. }\end{array}$ \\
\hline \multicolumn{3}{|r|}{ Isabel } \\
\hline $\begin{array}{l}1 . \\
2 . \\
3 .\end{array}$ & $\begin{array}{l}\text { Família normal; } \\
\text { Esposo trabalhava muito; } \\
\text { Mãe era dona de casa e cuidava dos filhos. }\end{array}$ & $\begin{array}{l}\text { 1. } \quad \text { Mãe passa a buscar a Igreja; } \\
\text { 2. } \quad \text { Esposo se sente culpado pela morte do filho; } \\
\text { 3. } \quad \text { Filho ficava em silêncio após a morte do irmão; } \\
\text { 4. } \quad \text { A estrutura familiar alterou de forma positiva após a } \\
\text { chegada da filha mais nova. }\end{array}$ \\
\hline \multicolumn{3}{|r|}{ Conceição } \\
\hline $\begin{array}{l}1 . \\
2 . \\
3 .\end{array}$ & $\begin{array}{l}\text { Família unida; } \\
\text { Esposo trabalhava muito; } \\
\text { Mãe dedicada a família. }\end{array}$ & $\begin{array}{l}\text { 1. } \quad \text { Esposo chorava muito; } \\
\text { 2. } \quad \text { Esposo foi a óbito após dois anos; } \\
\text { 3. } \quad \text { Irmã sofreu muito com a ausência do irmão; } \\
\text { 4. } \quad \text { Mãe relata ter medo de perder a filha "porque agora só } \\
\text { tem ela". }\end{array}$ \\
\hline \multicolumn{3}{|r|}{ Francisca } \\
\hline $\begin{array}{l}1 . \\
2 . \\
3 .\end{array}$ & $\begin{array}{l}\text { Esposo deixa a família; } \\
\text { "J" não aceita a separação dos pais; } \\
\text { "J" achava injusto a mãe trabalhar para } \\
\text { r a família; } \\
\text { A filha mais nova sempre foi o equilíbrio da }\end{array}$ & $\begin{array}{l}\text { 1. } \quad \text { Filha casa; } \\
\text { 2. } \quad \text { Mãe vai morar com a filha e o genro; } \\
\text { 3. } \quad \text { A neta nasce. }\end{array}$ \\
\hline \multicolumn{3}{|c|}{ Rita de Cássia } \\
\hline $\begin{array}{l}1 . \\
2 . \\
3 .\end{array}$ & $\begin{array}{l}\text { Família amorosa; } \\
\text { Esposo alcoólatra; } \\
\text { Mãe depressiva; }\end{array}$ & $\begin{array}{l}\text { 1. Após quatro meses da morte de "JL" sua Avó paterna vai } \\
\text { a óbito "por tristeza"; } \\
2 . \quad \text { Esposo culpava a mãe pela morte do filho; }\end{array}$ \\
\hline
\end{tabular}




\section{Gravidez de "JL" complicada;}

5. “JL" nasce uma criança saudável;

\section{Houve a separação;}

4. Em seguida o casal voltou a residir junto;

5. Após cerca de nove meses esposo é diagnosticado com câncer e vai a óbito;

6. Após a morte do esposo família apresenta dificuldade financeira.

\section{Aparecida}

1. Família normal;

1. Enfrentaram o luto juntos;

2. O esposo se isolou, ficou com a pressão arterial alta, teve isquemia, até hoje não se conforma com a perda;

3. A mãe apresentou-se forte quando se viu na responsabilidade de resolver tudo;

4. Filho ficou mais introspectivo;

5. "Nossa família ficou mais unida".

\section{Das Graças}

1. Família unida;

1. Família continua unida;

2. Mãe e dois filhos;

2. Os irmãos da mãe se aproximaram mais após sua perda;

3. "W" casou e me deu um neto;

3. A filha tornou-se a companhia da mãe.

4. Havia ajuda mútua.

\section{Rosa Mística}

1. Família normal e unida.

1. Avó de "P" ficou muito revoltada, não aceitava a morte;

2. Esposo de "P" faleceu cedo;

2. Uma irmã da mãe se aproximou a família após a morte.

3. Família composta por "P", avó, tio, mãe e irmão.

3. O filho sofreu com a ausência, "P" representava a figura paterna para ele.

\section{Fátima}

1. Uma família de seis filhos;

1. Todos os membros da família ficaram muito abalados;

2. A neta, filha de "JA" dizia: papai está no céu;

3. Mãe alega que não tinha força para ficar de pé;

4. O esposo, cadeirante ficou mais doente;

5. Filha não conseguiu trabalhar por semanas;

6. A nora, namorada de "JA" deu apoio a toda família.

Fonte: Dados de pesquisa (2018).

Após a perda de um filho em casos de morte trágica a raiva pode protagonizar os primeiros momentos, manifestandose pela pessoa perdida por não ter se cuidado, pelo companheiro por não ter feito algo para evitar ou de si por acreditar que os cuidados foram insuficientes, uma fase do luto em que se busca uma justificativa à dor (Kovács, 2002).

A perda de um filho além de interferir no sistema familiar, tende a acarretar angústias individuais capazes de desestabilizar o grupo. O processo de luto é extremamente variável, em alguns casos pode durar mais do que imaginado. Ainda, pode gerar um misto de sentimentos como: raiva, alívio, desapontamento, culpa e abandono (Walsh \& Mcgoldick, 1998). 
Por conseguinte, com a morte de um filho, os pais precisam desenvolver cuidados em relação aos demais que ainda dividem o ambiente familiar, evitando transferir todas as expectativas destinadas ao filho perdido aos outros (Mcgoldrick, 1998). Além disso, a perda pode promover o estreitamento dos laços entre os membros enlutados promovendo relações de confiança e fortificando a base familiar para novas experiências (Hall, 1998).

\subsection{Primeiros momentos após a perda e as principais memórias da despedida}

Os relatos das despedidas são fundamentais na identificação de um enfrentamento saudável. Diante de uma situação geradora de estresse, torna-se possível identificar como cada mãe identificou os fatos e buscou sua forma de enfrentamento através do relato de suas lembranças (Quadro 2).

Quadro 2. Sentimentos, ações e memórias após a perda.

\begin{tabular}{|c|c|}
\hline \multicolumn{2}{|c|}{ Sentimentos evidentes após os primeiros momentos da perda } \\
\hline 1. Dor & $\begin{array}{c}\text { Maria, Conceição, Francisca e Rita de Cássia, Aparecida, Das Graças, Rosa } \\
\text { Mística e Fátima. }\end{array}$ \\
\hline 2. Culpa & Maria. \\
\hline 3. Desejo de justiça & Maria e Francisca. \\
\hline 4. Falta de perdão & Maria e Francisca. \\
\hline 5. Questionar o porquê a Deus & Isabel e Conceição. \\
\hline 6. Preocupação com o esposo & Isabel e Aparecida. \\
\hline 7. Evitava chorar & Isabel. \\
\hline 8. Desespero & Conceição, Rita de Cássia, Rosa Mística e Fátima. \\
\hline 9. Choro & Conceição e Fátima. \\
\hline 10. Ansiedade & Conceição. \\
\hline 10. Oração & Conceição. \\
\hline 11. Vazio & Isabel e Fátima. \\
\hline 12. Fragilidade & Rita de Cássia, Aparecida e Fátima. \\
\hline 13. Isolamento & Rita de Cássia e Fátima. \\
\hline 14. Ausência de força e animo & Rita de Cássia e Fátima. \\
\hline 15. Não acreditava & Das Graças, Rosa Mística e Fátima. \\
\hline 16. Grito & Rosa Mística. \\
\hline 17. Não me alimentava & Fátima. \\
\hline
\end{tabular}

\section{Principais ações e memórias após a perda}

1. Saudade

2. Perdão

3. Fé e oração

4. Caridade

5. Ouvir a voz do filho

6. Visita diária ao cemitério

7. Noites sem dormir
Maria, Isabel, Conceição, Francisca e Rita de Cássia, Aparecida, Rosa Mística e Fátima.

Maria.

Maria, Isabel, Conceição, Francisca e Aparecida.
Conceição.

Francisca e Fátima.

Isabel e Das Graças. 
8. Calma

9. Força
Das Graças e Rosa Mística.

Rosa Mística.

\section{Sentimento de paz pela devolução do Maria, Isabel, Conceição, Francisca, Rita de Cássia, Aparecida, Das Graças, filho (a) à Deus Rosa Mística e Fátima.}

Fonte: Dados de pesquisa (2018).

Diante das circunstâncias da morte de "I", "Maria" afirma ter sentido dor, culpa, desejo de justiça e falta de perdão, com o passar do tempo, as boas memórias de "I" fizeram com que "Maria" trilhasse o caminho da saudade, do perdão, da caridade e da fé.

"Isabel" diz ter perguntado o porquê da perda a Deus, ela se preocupava com a forma de enfrentamento do seu esposo e em ser forte evitando que seu filho a visse chorar "Durante uma semana todos os dias às 2 hs da madrugada eu acordava e diante do escuro da noite conseguia observar o brilho de uma estrela, " $R$ " estava lá, esses episódios foram me fortalecendo dia após dia".

"Conceição" conta que a espera pela chegada do corpo do filho foi angustiante, afirma que Deus já vinha a preparando para essa dor e que seu choro era de conforto. "Os dias foram passando e eu escutava ele me chamando: mãe!" Também é evidente em sua narrativa a busca constante pela religiosidade "sempre rezando a oração das mãos ensanguentadas, o oficio de Nossa Senhora e o terço das sete dores, e assim me confortava”.

"Francisca" diante da dor e da saudade desenvolveu o ritual de frequentar o cemitério na busca de ficar perto do filho morto "No início saia de casa 6 h da manhã para o cemitério e voltava às 10 h, por volta das 15 h da tarde voltava ao cemitério e ficava até às 17h. Fazia isso todos os dias, com exceção ao dia de finados que eu chegava ao cemitério às 5 hs da manhã e saia às 19hs da noite".

"Rita de Cássia" descreve seus momentos e memória de forma breve, mas evidencia "fiquei sem acreditar, muito frágil, me isolei. Sem força, sem ânimo".

Diante das situações "Aparecida" narra que foi difícil, mas ela se reergueu pela família "Me senti no fundo de um poço. Mas depois tive que me erguer, vi que se não levantasse o que restou da minha família iria ser enterrado junto com " $R$ ”, e por ela me levantei".

"Das Graças" expõe dores e calmaria, segundo ela "nos primeiros momentos eu não acreditava. Passei noites sem dormir, foi muito doloroso. Mas depois fui contagiada por uma calma, não sei de onde ela veio".

"Rosa Mística" narra como um grande choque. "Comecei a sentir falta de cada ação dele, a saudade se faz presente em cada detalhe e com o passar dos dias a saudade foi fazendo morada em minha vida e hoje vivo com ela até hoje".

Por fim, "Fátima" afirma que "não me levantava da cama, não me alimentava, não queria receber visita" isolando-se por muito tempo do convívio social.

\subsection{O tempo e a resposta emocional à perda de um filho}

O processo de adaptação ao luto está em compreender a perda e persistir em busca de um novo sentido. Não tem como afirmar que a aceitação que tende a aparecer será definitiva ou que não há uma aceitação plena pelo enlutado (Walsh \& Mcgoldrick, 1998).

Nos casos de perdas traumáticas, há possibilidade de nunca passar do estágio de aceitação e a depender de como o enlutado gerencia suas perdas, será determinante a forma como o luto será experienciado (Hall, 1998). O quadro 3 a seguir apresenta se houve ou não um tempo determinado para responder a perda do filho e quais essas respostas emocionais. 
Quadro 3. Tempo determinado e a resposta emocional à perda.

\begin{tabular}{|c|c|c|}
\hline $\begin{array}{l}\text { Não houve um } \\
\text { tempo }\end{array}$ & $\begin{array}{l}\text { Houve um } \\
\text { tempo }\end{array}$ & Relato \\
\hline Maria & - & "Não houve um tempo definido" \\
\hline Isabel & - & "A minha dor foi silenciosa, não teve tempo exato, cada dia era uma vitória" \\
\hline Conceição & - & "Não há uma resposta exata, simplesmente aceitei" \\
\hline- & Francisca & $\begin{array}{l}\text { "Passei três meses sem trabalhar, não saia para lugar nenhum. Após alguns dez anos a } \\
\text { dor amenizou mais, dá para conviver com ela" }\end{array}$ \\
\hline Rita de Cássia & - & $\begin{array}{l}\text { "Foi necessário muito tempo para que eu começasse a responder a perda, não sei o } \\
\text { tempo exato" }\end{array}$ \\
\hline- & Aparecida & $\begin{array}{c}\text { "Os dois primeiros anos foram os mais difíceis, acho que fui a mãe que mais chorou, até } \\
\text { hoje ainda choro muito" }\end{array}$ \\
\hline Das Graças & - & $\begin{array}{c}\text { "Às vezes ainda tenho a sensação que ele vai chegar em casa, me dá uma vontade } \\
\text { desesperada de chorar" }\end{array}$ \\
\hline- & Rosa Mística & $\begin{array}{l}\text { "Os primeiros meses foram os mais difíceis, porque nós tínhamos um laço muito forte, } \\
\text { ele era o meu filho caçula" }\end{array}$ \\
\hline- & Fátima & $\begin{array}{c}\text { "Por mais de dois anos eu fiquei na porta esperando ele chegar. Passei quatro anos sem } \\
\text { participar das festividades do meu trabalho". }\end{array}$ \\
\hline
\end{tabular}

Fonte: Dados de pesquisa (2018).

Dentre as nove mães entrevistadas Maria, Isabel, Conceição, Rita de Cássia e Das Graças afirmaram não existir um tempo determinado para responder emocionalmente a morte de um filho. Por sua vez, Francisca, Aparecida, Rosa Mística e Fátima relatam que existiram períodos de tempo necessários a construção dessa resposta emocional, mas não houve um tempo preciso, cada mãe elaborou de forma especifica a sua perda.

McGoldrick (1998) afirma que mesmo no luto traumático, há possibilidade de readaptação pelo enlutado. A paralisação da vida ocorre apenas quando a morte é negada devido à ausência de um novo sentido da vida. Ressalta-se que mães que perdem filhos repentinamente tendem a desenvolver o senso de irrealidade da perda necessitando-se, em alguns casos, de auxilio psicológico (Freitas, 2000).

\subsection{As principais mudanças na saúde física e mental geradas após a perda}

Quanto às mudanças devidas ao luto, as subseções seguintes caracterizam as mães que apresentaram alguma alteração ou não foram afetadas em nenhuma dessas possibilidades.

Mães que apresentaram mudança fisica

Duas mães relatam ter apresentado mudanças físicas após a perda do filho. A primeira foi "Conceição", relatando alteração na pressão arterial e o início do tratamento da arritmia cardíaca. "Minha pressão arterial ficou alta, mas foi apenas no momento de maior emoção. Eu já tinha arritmia cardíaca, desenvolvi antes das perdas, mas só há um ano comecei o tratamento através de medicamento".

"Rosa Mística" afirmou ter desenvolvido labirintite: "desenvolvi um tipo de labirintite, fiquei debilitada, me isolei, não sentia vontade de me alimentar". 
Mães que apresentaram mudança psicológica

Quatro mães afirmam apresentar mudanças psicológicas. "Maria" e "Isabel" queixam-se de sensibilidade em excesso, "Rita de Cássia" e "Fátima" relatam o desenvolvimento da depressão (Quadro 4).

Quadro 4. Mudanças psicológicas.

\begin{tabular}{|c|c|}
\hline Mães & Relato das mudanças psicológicas \\
\hline Maria & "fiquei mais sensível" \\
\hline Isabel & "hoje estou muito sensível para tudo" \\
\hline Rita de Cássia & "a depressão voltou muito forte" \\
\hline Fátima & "entrei em depressão, chorava diariamente, fiquei muito esquecida, não aguentava trabalhar, não \\
& conseguia dormir. \\
\hline
\end{tabular}

Fonte: Dados de pesquisa (2018).

Segundo Kübler-Ross (2008) a depressão é faz parte de um dos estágios do luto, ela pode ser classificada em reativa (desenvolvida de acordo com a dor e o sofrimento gerados pela perda) e preparatória (estrutura-se na mente as perdas que tendem a acontecer em um período curto de tempo).

\section{Mães que apresentaram mudanças físicas e psicológicas}

"Francisca" foi a única que apresentou em sua narrativa mudanças físicas e psicológicas "me tornei hipertensa $e$ desenvolvi problemas de circulação, o médico falou que foi devido o sofrimento. Eu também ficava calada e não queria sair. Até hoje eu não sei porque não tive depressão".

\section{Mães que apresentaram nenhuma mudança}

Outro cenário apresentado por duas mães foi a ausência de manifestação de doenças. "não desenvolvi nenhuma doença, graças a Deus" ("Das Graças") e "não senti reação física nem mudança emocional brusca" ("Aparecida").

Sendo assim, é possível identificar que não há um fato exato quanto à existência ou não de mudanças. O estudo indica que a dor é sentida e vivenciada diferentemente pelas mães.

\section{Conclusão}

Como estratégia de prevenção de doenças físicas e mentais existe períodos considerados normais para vivenciar a dor da perda com "normalidade" sem desenvolver consequências negativas ao corpo e a mente. No entanto, a forma de enfrentamento pode refletir nas conflagrações que serão necessárias para superar a dor.

A narrativa da amostra estudada permitiu identificar que o luto foi experienciado de forma individual, autêntica e particular. Um ponto relevante nas narrativas referiu-se ao sentimento de culpa pela morte do(a) filho(o). Ainda, verificaram-se transformações na forma dessas mães enlutadas observarem o mundo após a perda do(a) filho(a). Ademais, a pesquisa apontou que na maioria das relações familiares ficaram mais consolidadas. Outro dado relevante refere-se às ações espirituais, mais presentes no cotidiano materno. Enfatiza-se que mesmo após a devolução do(a) filho(a), o vínculo de mãe permaneceu inalterado e novas formas de ligação com o ente querido foram desenvolvidos.

Também foi possível identificar que o apoio familiar, a espiritualidade, a continuidade do vínculo com o filho falecido, a interação e o desenvolvimento de ações através do grupo foram fundamentais na reconstrução de sentido da vida. Tendo em vista a natureza delicada do assunto que permeia a pesquisa, é possível afirmar que estudar sobre temas que 
envolvem morte, perda e luto materno é complexo, porém tais pesquisas são fundamentais à medida que permitem auxiliar outras mães que sofrem da "dor sem nome" a superar e reencontrar sentido.

Por fim, sugere-se o desenvolvimento de novas investigações sobre o objeto de estudo, bem como sejam criados grupos de apoio para pessoas enlutadas.

\section{Agradecimentos}

Agradecemos as mães que participaram deste estudo.

\section{Referências}

Aquino, T. A. A. (2013). Logoterapia e Análise existencial. Paulus.

Aquino, T. A. A. (2014). A presença não ignorada de Deus na obra de Viktor Frankl. Paulus.

Bardin, L. (1979). Análise de conteúdo. Lisboa, Edições 70.

Benjamin, W. (1994). O narrador: considerações sobre a obra de Nikolai Laskov. In Magia e técnica, arte e política: ensaios sobre literatura e história da cultura. Obras Escolhidas, 1. Brasiliense.

Bowlby, J. (1989). Uma base segura. Artes Médicas.

Bromberg, M. H. P. F. (2000). A psicoterapia em situações de perdas e luto. Editora Livro Pleno.

Fonnegra, I. (2001). De cara a la muerte. Cómo afrontar las penas, el dolor y la muerte para vivir plenamente. México: Andrés Bello.

Frankl, V. E. (1978). Fundamentos antropológicos da psicoterapia. Zahar.

Frankl, V. E. (1991). Psicoterapia na prática. Papirus.

Frankl, V. E. (2011). A vontade de sentido: Fundamentos e aplicações da Logoterapia. Paulus.

Freitas, N. K. (2000). Luto materno e psicoterapia breve. Summus.

Friedman, E. H. (1995). Sistemas e cerimônias: Uma visão familiar dos ritos de passagem. Em McGoldrick. M. \& Carter, B. (Orgs.). As mudanças no ciclo de vida familiar (pp. 106-130). Artes Médicas.

Fonseca, R. S. S. (2014). Fenômeno Religioso Paraibano: Uma Análise Mítica da Igreja de Santo Antônio. Dissertação de Mestrado, Mestrado em Ciências das Religiões, Universidade Federal da Paraíba, João Pessoa -PB.

Hall, J. B. (1998). Os roteiros familiares e a perda. In: Froma, W., \& McGoldrick, M. Morte na Família: sobrevivendo às perdas. Artmed.

Kovács, M. J. (1992). Atitudes diante da morte: visão histórica, social e cultural. In: M. J. Kovács, M. J. (org.) Morte e desenvolvimento humano. Casa do Psicólogo, São Paulo.

Kovács, M. J. (2002) Educação para a morte: desafio na formação de profissionais de Saúde e educação. Tese de Livre Docência - Instituto de Psicologia Universidade de São Paulo.

Kübler-Ross, E. (2008). Sobre a Morte e o Morrer. Martins Fontes.

McGoldrick, M. (1998). Morte na família: sobrevivendo as perdas. ArtMed, p. 166-186.

Melo, A. S. E., Maia Filho, O. N. \& Chaves, H. V. (2014). Conceitos básicos em intervenção grupal. Encontro: Revista de Psicologia, 17(26). https://revista.pgsskroton.com/index.php/renc/article/view/2414.

Minayo, M. C. S. (2010). Pesquisa social: teoria, método e criatividade. (29a ed.), Vozes.

Minuchin, S. (1982). Família, Funcionamento e Tratamento. Artes Médicas.

Moreira, N. \& Holanda, A. (2010). Logoterapia e o sentido do sofrimento: convergências nas dimensões espiritual e religiosa. Psico-USF, 15(3), 345-56. https://www.scielo.br/scielo.php?script=sci_arttext\&pid=S1413-82712010000300008

Parkes, C. M. (1998). Luto: estudos sobre a perda na vida adulta. Summus.

Suárez, L. D. A. B., de Sousa, M. N. A., \& Caldas, M. T. (2020). Entre flores e sepultura: a maternidade e o processo de perda de um filho. Revista Brasileira de Educação e Saúde, 10(3), 23-30.

Walsh, F. \& McGoldrick, M. (1998). Um tempo para chorar: A morte e o ciclo de vida familiar. In: F. Walsh \& M. McGoldrick (Ed.). Morte na família: Sobrevivendo às perdas (pp. 56-77). Artmed. 